\title{
Project Design Management for a Large Hydropower Station
}

\author{
Xuanhua $\mathrm{Xu}$, Yanju Zhou and Xiaohong Chen \\ School of Business, Central South University, \\ People's Republic of China
}

\section{Introduction}

"Hydropower Engineering Design" refers to a whole process, which is undertaken by the design company commissioned by the project owner and includes the following:

- The initial stages covering mapping, survey, exploration and experiment.

- The use of high technology knowledge, taking into consideration the fluvial landform, geological conditions and social economics of the project location.

- Being subject to repeated research and scrutiny by particular engineering and technical personnel.

- $\quad$ Preparing and presenting the design scheme for the project phases.

- Preparing written reports and blueprints.

- The revision and improvement of the design scheme to the point of complete approval or ratification by the owner, adjudication units and various departments.

The typical characteristics of a hydropower design enterprise include a very large management organization, numerous personnel, low efficiency, heavy social burden, and slow technical progress. Consequently a hydropower project design method of production management with a supporting information system is needed which is suitable both for the operation of the design enterprise and competing internationally. The management approach should improve efficiency to face market challenges and ensure survival.

Based on the principles of system engineering and information technology, according to the actual needs of engineering design and project production management, changing and complex hydropower project design can be divided into relatively simple production processes. These processes can be integrated into an overall project production process control system by the use of information technology. The goal of the set of production processes in management control of technology is to simplify complex issues, to standardize simple problems, to sequence standard processes and then to apply information technology to the sequencing procedure. In actual production processes, project decision makers modify the process network parameters and adjust the critical path of process control, according to the production plan and actual progress. This enables the achievement of dynamic management, rapid decision-making and rapid adaptation to changes in the market.

A large hydropower project always faces the following problems: enormous scale of construction, long period of construction, huge investment and high risk, and numerous 
participating units and personnel. These problems also mean higher requirements for project management for which information technology becomes a more critical factor in project design management methodology. Thus, there is a need to establish a hydropower station design project production management system which has project design as its core business. At present, the widely used P3 platform application focuses mainly on the project planning and control of the engineering construction of large hydropower stations [1-3], on early systems of management information data exchange and integration [4-5], and on petroleum engineering applications [6]. This book presents a method based on the P3E/C platform with the design of the construction of a large hydropower station project as the core of the project management system and its implementation methodology. This enables support for the improvement of large hydropower station project design and production efficiency. At the same time, it also provides references for applying information technology to the production management of large hydropower station design projects.

Aiming at the complexity and therefore increased understanding of design projects for hydropower stations, this chapter analyzes in depth the design processes and characteristics of projects for large hydropower station engineering and puts forward a method of breaking down complex \& cyclically changing design processes into a series of relatively simple work procedures or packages of work procedures. The application of information technology to documenting the work procedures and outputs, can realize the control of the design production process, quality control of design processes and products, management of staff performance, product statistics and archiving. The establishment of a production information management system should improve and optimize the design process, and continuously improve the management methods of the design project and the operational efficiency of the company. Therefore, based on the project of a large hydropower station designed by Hydrochina Zhongnan Engineering Corporation, we demonstrate the production management system of a large hydropower station design project using the P3E/C. This approach frames the network structure, and the system running platform puts forward a methodology for the following four technologies key to realizing the system: decomposition of the design process and work-procedure structure, circulation of project work-procedure sheets, generation of a dynamic matrix network diagram, and project production safety processes. Furthermore, also based on P3E/C, it proposes the methodology for realizing the three core sub-systems of project schedule management, activity process management, and working staff performance management.

\subsection{Hydropower engineering design characteristics}

The production of a hydropower station construction design project is essentially different from that of common goods production. The design project is more involved in intellectual work, while the project outcomes or products result in various drawings and paper documents. This invariably involves many complex design processes and numerous technical staff. Due to high professional demands and the knowledge required, it is difficult to control the production process and estimate personnel performance. This situation directly affects the quality, progress and efficiency of the construction design project. For example, the Mid-South Design \& Research Institute of China (MSDRI) is a professional research institute engaged in Hydropower Station Construction Project Design. MSDRI has successfully designed the Hydropower Stations of Hunan Wuqiangxi, Xiangjiaba, Longtan, Fengtan, Dongjiang, and Youchou as well as other large to medium-sized hydropower 
stations. The MSDRI has established its own local area computer network (LAN) which is equipped with advanced servers and associated equipment. It has also developed a web-site and comprehensive management information system. However, the engineering design business management of hydropower station design in MSDRI is still a combination of manual process control with computer software design document processing. Specifically, the hydropower engineering design characteristics are outlined below.

\subsubsection{Knowledge-intensive intellectual work involved with multiple technologies}

Hydropower engineering design is a type of knowledge-intensive intellectual work. Inside the design company, the specialties include geology, exploration, hydrology, planning, water and construction engineering, mechanical and electrical engineering, reservoir resettlement and environmental protection, scientific research and experimental work, construction, operations, HVAC, fire-fighting, safety evaluation, soil and water conservation, engineering quantity surveyors and cost accountants and other professional staff. According to the needs of their professional work, qualified designers should have a good understanding or be familiar with the relevant knowledge of economics and management. In addition they need to be expert or knowledgeable in one of the following professions: hydrology and water resources, electric power system, engineering design, engineering geology and hydrological geology, land management, asset valuation, city planning, traffic engineering, power engineering, regional planning, agriculture, forestry, environmental ecology, biology (aquatic and terrestrial organisms), soil, hydraulics, aerographics, river kinematics, risk assessment theory, structural mechanics, material mechanics, elastic mechanics, hydraulic machinery and engineering machinery, electronic science, simulation theory, and the theory and method of general budget estimating, etc.

\subsubsection{Work content, multiple agencies involved and wide social influences}

Survey, design and research are the three main components of Hydropower project design, and the detailed work includes field surveying, investigation and research, in-door design, and consultation, assessment, review, on-site services, etc. Investigation and research content relates to the various departments of social, economic, environmental, nature, national economy and so on. It also needs to mobilize large numbers (possibly hundreds) of people to work for months or years to complete the task. The whole process of design also has very wide social influence.

\subsubsection{Obvious division of work stages and governmental dominance}

Several problems arise during the construction of hydropower stations, such as the occupation of large amounts of land (especially cultivated land and gardens) and migrant resettlement. Some problems involve cross-region resource development, immigration, taxes and reservoir operation management. The capacity of a hydropower station can range from millions of cubic-meters to tens of billions of cubic-meters. In this environment, any major accident could cause huge loss of life and property downstream. Therefore, the government has set up strict regulations for the necessary working stages of hydropower station construction including: river planning, pre-feasibility study, feasibility study, design bidding, construction blueprint design, completion and final acceptance. The later stages cannot be started until previous stages have been approved. 


\subsubsection{Quality products are based on collective wisdom \& team spirit}

Subject to the complex professional structure, cyclic and changing work-procedures, and based on the proposed scheme, professional personnel participate in the design of the hydropower station project in a coherent, and generally co-ordinated manner under the guidance of a chief engineer. Chief design officers and chief engineers, finding problems in completing their individual professional work, then modify and optimize the design scheme, and finally summarize their recommended scheme after repeated comparison and scrutiny. A good scheme and quality product can only be born out of the wisdom of the professional experts combined with the close cooperation of a large number of designers.

\subsubsection{Products appear as information products such as drawings or electronic documents}

Different from industrial products in physical form, design products appear as information detailed in written reports, drawings or electronic documents. In order to realize their functional requirements or value, industrial products can be directly used by the consumer while the design product for a hydropower station project needs to be carried out by processes of construction and resettlement of people affected.

\subsubsection{Each of the various types of projects requires individual effort of survey and design}

Hydropower stations can be located on different rivers and on different locations on the same river. Each of them confronts different terrain and geological conditions. The amount and difficulty of construction land requisition and resettlement for each station is typically not the same. Differences are also apparent in the range of power supplies, the transmission distances, the scale of engineering construction and the layout and form of engineering buildings. Accordingly, survey and design research work must be separately aimed at each project in order to make the design products suitable for the requirements of the geological and topographical conditions, local social and economic conditions, and actual power supply demands.

\section{Key technologies of production process control}

To efficiently complete the project design production within given time frames, four key factors need to be dealt with: A. Decomposition of the design process and process hierarchy. This solves problems for design project identification and feasibility. B. Communication of the implementation of the project process. This deals with responding to questions on the process control of the project design and of the design personnel. C. Realization of a dynamic matrix network graph. This is concerned with the schedule control of the project production. D. Realization of project product safety management, which includes the settlement of project product copyright issues.

\subsection{Decomposition of design process and working-procedure hierarchy}

\subsubsection{Hydropower station project design processes and their internal structure}

The whole process of hydropower station design can be divided into the following main production procedures: selection of the location, waterline and type of the dam, hydro- 
junction layout research, project scale arguments (concerns the normal water level, limit water level for flood periods and flood demonstrations, dead storage level choice, and the selection of installed capacity), design work for the selected scheme, report generation, evaluation and consultation, reviews and revisions, work completion, etc. Within each of the main production processes above, there are unique design professions involved, various professional force inputs, different focus and information accuracy. Each professional work activity has its own sequences, provides mutual information and contributes to mutual authentication.

The project design process is complex, and the multilayer production plan based on P3E/C can solve and coordinate this complex problem. Through the work breakdown structure (WBS) we define:

- Activities (operations, activities or tasks can be organized into package of work procedures)

- $\quad$ Steps (steps within operations)

The senior management layer starts top-down planning, while the base-level of the project team carries out bottom-up decomposition for the project plan. A harmonious and unified plan is then formed with milestones suitable for the needs of different management levels (P3E/C can recognize the milestones layers). Different levels of the program reflect different focuses of attention and measures that need to be taken to ensure communication consistency and validity between all levels of management and/or between the project team and external related units. This enables the plan to guide and control the project implementation process.

According to the project design characteristics, the design company's WBS system is formed as a tree structure. This system, using a set of coordinated process codes, integrates complicated production processes into an organic production process control model which assumes the project plan controls as the main activities, and then adds on quality control, product transfer and management, performance appraisal in the program execution process, and finally forms the production management information system.

\subsubsection{Hierarchical structure of work-procedures for hydropower station project design}

A hydropower station is designed in terms of project management, professional division, and professional offices which progressively extend to enterprise level. It can be divided into three levels.

For the first level, the main production processes must be set up. These processes, which include various professional offices providing product exchange links outside the office, are the focus of project management at the enterprise level (including the leader in charge, administrative department, project manager, chief design officer etc.).

The second level is to set up internal production processes in professional divisions. These processes, which include controlling product exchange links internal to the professional division, are the focus of project management at the division level (including the leader in charge, specifically general managers, and main designers).

At the last level, the product submission links in various professional offices are designed. They are the key point of control for the main designer and leaders in the professional office. 
Certain feedback work-procedures (such as project selection) in various professional divisions can follow the work-procedure approach of the management package.

Figure 1 roughly describes the process of the above hierarchical structure. At the same time, the C13 professional internal structure and its subsidiary specialized work-procedures are also presented in the diagram. Different professionals may launch the work-procedure structure according to their own actual situations.

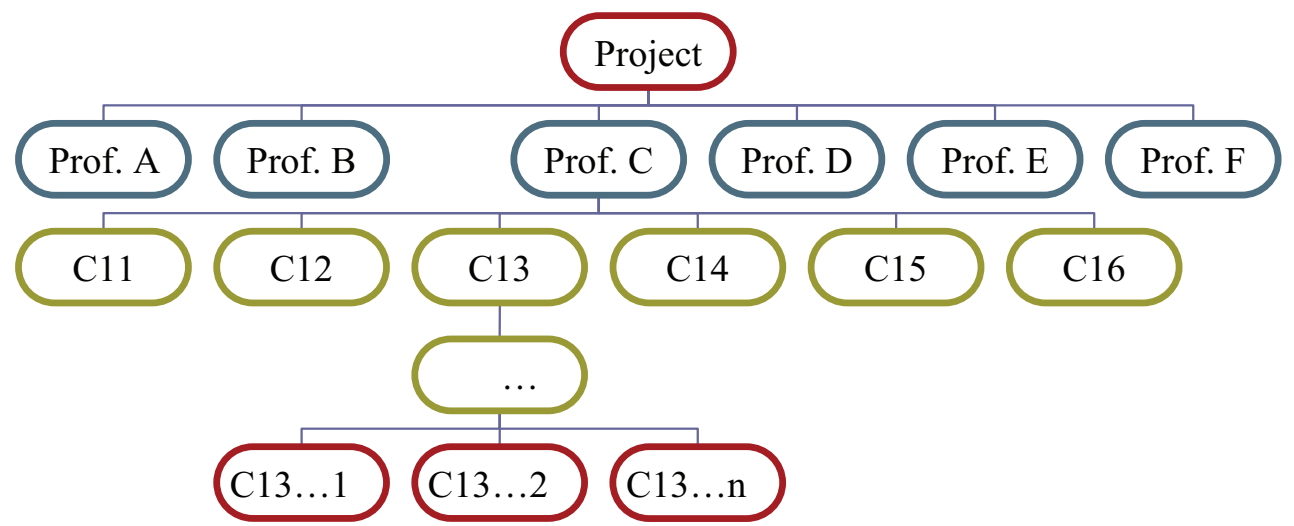

Fig. 1. Working-procedure hierarchical decomposition structure diagram of hydropower station project design (Note : Prof.=Profession).

\subsubsection{Work-procedure structure}

Work-procedure structure must be standardized, otherwise, neither are the input/output parameters measured nor is the quality of the results in the work-procedures controlled. The basic model of the process structure is as shown in Table 1 . The work-procedure structure pattern includes the following main contents.

\section{The application of the design process}

Some work-procedures occur only in certain or a few design processes. For some professionals, some processes are not relevant, i.e. there is no process. Most of the professionals in various design processes have work and design processes. However, for different professionals at different stages of the design process, these design processes differ from each other in terms of the input workload, requirements for precision in the results which is built into the procedure as a basis for the work, and the focus of the different professionals.

The work-procedure structure requires that various professionals are divided by unified design processes in accordance with their own situation, and break down the work in different design phases into various design processes. The final product of a previous design process provides the basis for the work and input conditions of the next design process. With the gradual deepening of the design process, the design process focus, work depth and product quality requirements become clearer. The end of a design process represents completion of the design work in a certain phase.

2. The encoding work-procedure and its significance 
Only the complex work-procedure work in coded representation can be described in mathematical terms for use by the main network in information system control. Each workprocedure corresponds only to its corresponding coding which has a specific meaning.

\begin{tabular}{lllllll}
\hline $\begin{array}{l}\text { Application } \\
\text { of design } \\
\text { process }\end{array}$ & $\begin{array}{l}\text { Encoding } \\
\text { work- } \\
\text { procedure }\end{array}$ & $\begin{array}{l}\text { Work- } \\
\text { procedure } \\
\text { name }\end{array}$ & $\begin{array}{l}\text { Information } \\
\text { input }\end{array}$ & $\begin{array}{l}\text { Rules } \\
\text { procedure } \\
\text { parameters }\end{array}$ & $\begin{array}{l}\text { Work } \\
\text { time }\end{array}$ & $\begin{array}{l}\text { Output QC } \\
\text { putput } \\
\text { orient- } \\
\text { ation }\end{array}$ \\
\hline
\end{tabular}

Table 1. The working procedure structure of professional design stage.

3. The work-procedure name and output products

The work-procedure name is an abbreviation of the work content in a process, which should align with the output product in the process. Each procedure corresponds to a product (process) or a variety of products (process package), although the product may be repeated a few times (such as when comparing the results of a scheme). However, its occurrence should be used as product to be managed every time. There are two reasons for this. One is to make it easy to track back, the other is to facilitate measurement.

4. The information input in the work of the work-procedures

The working conditions are input conditions in the process. These conditions include the basis of the work which is necessary for work completion. The basis of the work can be either created by organizers, such as stipulating a design principles guide book, outline design, professional design rules or proposed design, or the output product or result provided by the previous step. The operator cannot complete the process successfully without clear information input.

5. The work content and rules in the process

In the process of decomposition, the effective links in the whole design process must be taken fully into consideration. A single work process, under certain conditions for one person, is classified as one step in the process, so as to reduce disputes over trifles, clarify responsibility and set up convenient measurement and assessment metrics. The rules of work mean principles and methods which comply with prescribed requirements in the work content, such as design procedures, standards, design handbook, reference books or relevant documents. Designers should master the work content and apply it in a flexible way, to complete the job quickly and accurately. The process structure table must clearly indicate or establish the principles and methods on which the work procedure is based, to identify the basis for proofreaders to complete their work.

6. The work-procedure parameters

Work-procedure parameters can be set according to the management level of the enterprise, the characteristics pertinent to the engineering project and the allocation system of the enterprise. In general, they should include the basic work time parameters which are involved in the work content, the job complexity parameters which are involved in the same work content of a different project, and any repetition or rework parameters, etc.

7. Work time 
The work-procedure operation-time parameters (converted into operation time on a regular basis) are set down and chosen according to the production level of each professional office. However, specific projects are provided for in the total work time for the contract, therefore according to the specific circumstances of the project design, uniform adjustment of all professional work time parameters is required to meet the owner and contract requirements.

8. Quality control

The functions performed by different process products will always vary either in different stages of the same project or in different design processes in the same stage, so a control methodology for the quality of outputs may be different in each case. The control methodology for process products can be established according to its required quality management characteristics and specific process classification.

\section{Output orientation}

In the work-procedure structure, the output point must be made clear in every process. It is convenient for the system to conform to the specified work-procedure which follows the given direction, as the work input condition.

\subsubsection{Transfer process for work-procedure sheet}

The work-procedure sheet is the core data structure of the system, which represents not only the work-procedure content and logical relationships, but also the important basis for calculating project duration and personnel performance. Table 1, the work-procedure structure table according to its circulation needs refinement, as shown in Table 2. One of the key issues in design project management is to realize the circulation of the work-procedure table in the system.

\begin{tabular}{|c|c|c|c|c|c|c|c|c|c|c|c|c|c|}
\hline \multirow{3}{*}{$\begin{array}{l}\text { Application of } \\
\text { design process }\end{array}$} & \multirow{3}{*}{\begin{tabular}{|c|} 
Encoding \\
work- \\
procedure
\end{tabular}} & \multirow{3}{*}{$\begin{array}{l}\text { work-procedure } \\
\text { name }\end{array}$} & \multicolumn{3}{|c|}{ Input (Work Condition) } & \multicolumn{2}{|c|}{ work-procedure Work } & \multicolumn{6}{|c|}{ Quota Work-day } \\
\hline & & & \multirow{2}{*}{\begin{tabular}{|c|} 
Input \\
Profession
\end{tabular}} & \multirow[t]{2}{*}{ Code } & \multirow{2}{*}{$\begin{array}{c}\text { Input } \\
\text { Content }\end{array}$} & \multirow[t]{2}{*}{ Content } & \multirow{2}{*}{$\begin{array}{c}\text { Basis } \\
\text { (Standard \& } \\
\text { Fomula) }\end{array}$} & \multirow{2}{*}{$\begin{array}{c}\text { Basic } \\
\text { Work-day }\end{array}$} & \multirow{2}{*}{\begin{tabular}{|c} 
Difficulty \\
Level
\end{tabular}} & \multicolumn{2}{|c|}{ Repeated Coefficient } & \multirow{2}{*}{$\begin{array}{c}\text { Conversion } \\
\text { Coefficient } \\
\text { K }\end{array}$} & \multirow{2}{*}{\begin{tabular}{|c} 
Counted \\
Work-day
\end{tabular}} \\
\hline & & & & & & & & & & $\begin{array}{l}\begin{array}{l}\text { Number } \\
\text { of Times }\end{array} \\
\end{array}$ & Coefficient & & \\
\hline $\begin{array}{c}\text { Hydrogeological } \\
\text { investigation test } \\
111\end{array}$ & 11101 & $\begin{array}{c}\text { Water quantity } \\
\text { investigation }\end{array}$ & & & & $\begin{array}{c}\text { Water quantity } \\
\text { investigation }\end{array}$ & & & 2 & 1 & 0.8 & & \\
\hline
\end{tabular}

Table 2. a) The working-procedure table of professional stage.

\begin{tabular}{|c|c|c|c|c|c|c|c|c|c|}
\hline \multicolumn{2}{|c|}{ Design } & \multicolumn{4}{|c|}{ Proofread Scale } & \multicolumn{4}{|c|}{ Output(parameter or achievement) } \\
\hline \multirow{2}{*}{ No. } & \multirow{2}{*}{ Coefficient } & \multirow{2}{*}{ Proofreader } & \multirow{2}{*}{ Chief in Profession } & \multirow{2}{*}{ Chief Design Officer } & \multirow{2}{*}{ General Chief } & \multirow{2}{*}{ Content } & \multicolumn{2}{|c|}{\begin{tabular}{|r} 
Reciever \\
\end{tabular}} & \multirow{2}{*}{ Code } \\
\hline & & & & & & & Profession & No. & \\
\hline & & 365 & 178 & & & $\begin{array}{l}\text { Achievements of water quantity investigation } \\
\text { (investigation files, Calculation \& analysis draft, } \\
\text { Drawing, similarly hereinafter) }\end{array}$ & & & 11055 \\
\hline
\end{tabular}

Table 2. b) The working-procedure table of professional stage.

The work-procedure table contains many data fields: code, input / output, working documents, difficulty coefficient, overlap coefficient, conversion coefficient. The process table is set up in a framework for circulation in the system to the completion of production for the design project. However, P3E/C does not correspond to the table directly, but this can be achieved through customization and matching the process table with the project operation. Because P3E/C operations include many attributes, some correspond to part of the data field in the process table, such as code, input/output, and working documents. However, a certain number of data fields in the process table, such as the difficulty 
coefficient, overlap coefficient, conversion coefficient and etc., have no direct corresponding attributes in the P3E/C operation, which was achieved through custom fields in P3E/C. Custom fields can be either global or constrained. By adding custom fields into the operation, all the data in the process table are mapped into the attributes of $\mathrm{P} 3 \mathrm{E} / \mathrm{C}$, thereby realizing the successful circulation of the work-procedure table in the system.

Circulation control of the work-procedure table is realized through the P3E/C program, which contains project management (PM) and project reporting (PR) components. The PM implementation is used to make work-procedure table creation, distribution, and feedback on supply and demand indices a reality. P3E/C provides a variety of ways to achieve this. One is to log onto the PM main module which feeds back the completion time, the percentage of completion of the task and resource quantities in a given period. The other way is to $\log$ onto the Progress Reporter. The latter method is recommended, because it consists of a B/S structure which is very suitable for feedback on remote design work in progress. On the feedback interface of the P3E/C work-procedure sheet, the task for user involvement is listed automatically in this period. Users can: a) record the actual opening and completion time; b) obtain information from the project manager, while also giving feedback to the project manager; c) record the task log on a note book; d) articulate task related documents; e) give detailed feedback on accomplishments; f) fill in the form describing a single task, actual work hours for each day or each week. Once finished and submitted, this form cannot be edited further, and waits for approval.

\subsubsection{Realization process for the dynamic matrix network graph}

The dynamic matrix network graph is the core of project progress control. The single-code network diagram (PDM) is used to represents the logical relationships of the various

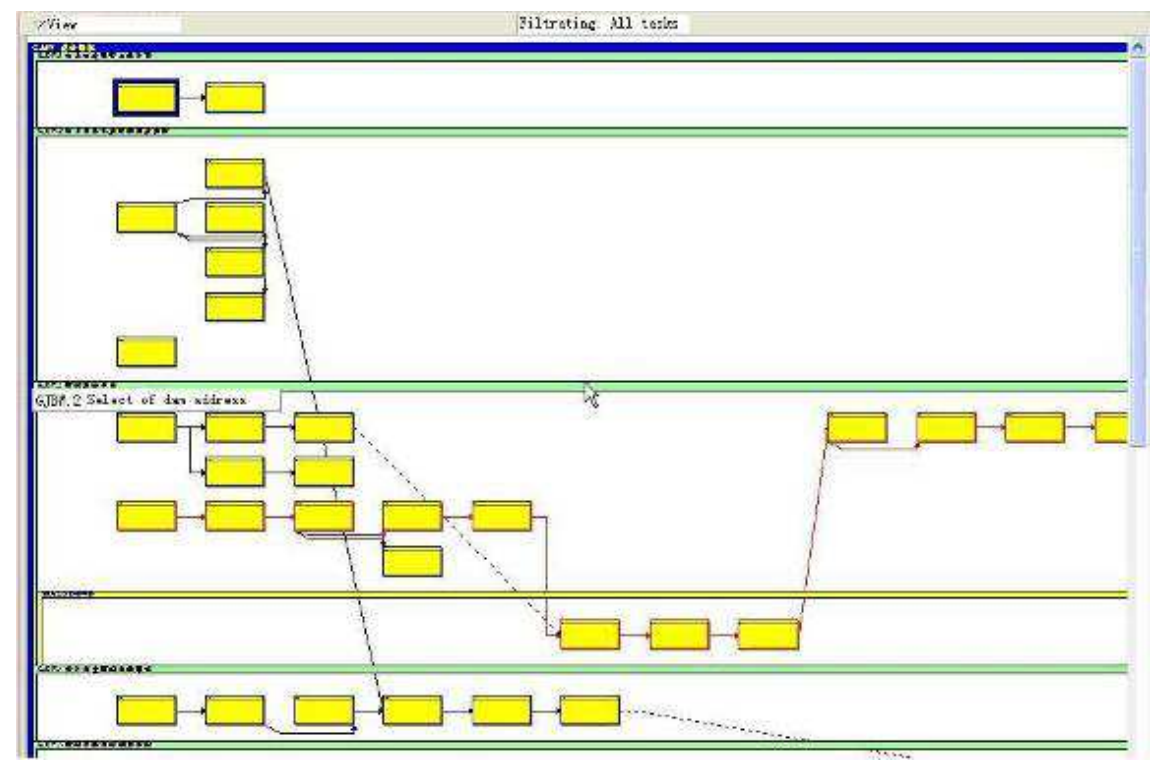

Fig. 2. Schematic diagram of an activity dynamic matrix network. 
processes in the P3E/C. Data in the network graph is from WBS (project decomposition) and the definition of operation. Not only the time limits for a project require to be defined but so do the logical relationships in operation. In the P3E/C operation, the logical relationship in operation can be defined as four types: finish to start (FS), start to start (SS), finish to finish (FF), and start to finish (SF). These relationships are set in the job attributes. With WBS, operation and operation logic, $\mathrm{P} 3 \mathrm{E} / \mathrm{C}$ generates the project network diagram automatically and will use a direct or adverse method to calculate the critical path. When the job attributes (such as the time limit for a project, the modified logical relationships) are set, the network will dynamically update. The PDM of P3E/C is shown in Figure 2 (the red line represents the critical path).

\subsubsection{Realization process for the safety management of a design project product}

The main products of the design project are various types of documents or computational drafts. This kind of product is easy to copy, so product safety management is a very important component of design project management. The process is achieved by using role safety management strategies provided by P3E/C, which the user directly associates with Enterprise project structure (EPS), organization breakdown structure (OBS) and WBS. The safety management strategy for a design product is shown in Figure 3.

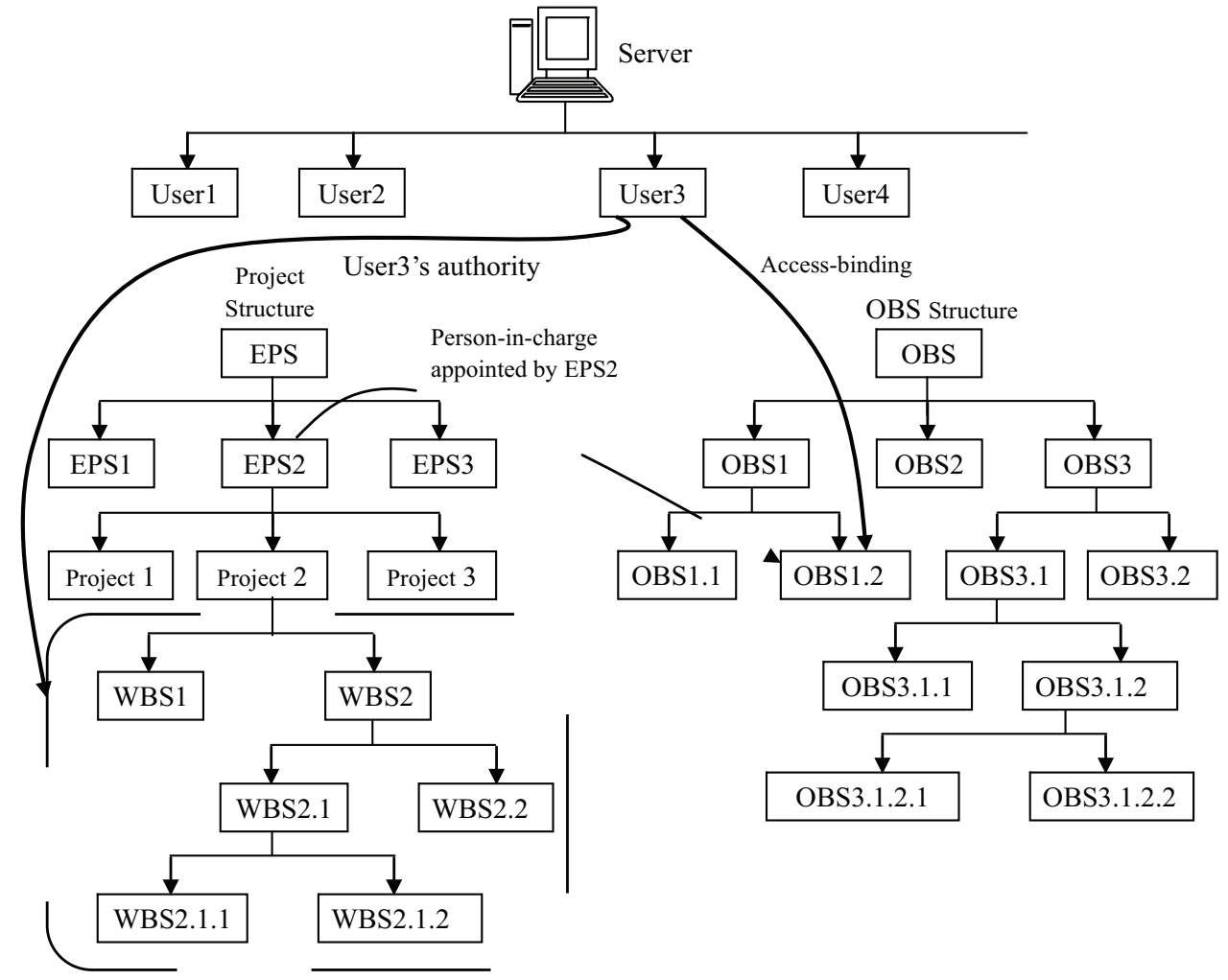

Fig. 3. Schematic diagram of product safety system for design project. 
The user's rights depend on his level in the OBS, and the projects (or WBS) assigned to related organization level (such as a Department) in the project structure. Therefore, the privileged management of a project makes its definition simultaneous with EPS, OBS, and WBS, which maintains communication with the entire project structure.

In addition, using document management in an individual work center of P3E/C, can easily deal with the approval process of the design product, and the process documentation and management needs of the document version, view, download, and security audits.

\subsection{System platform construction}

\subsubsection{System network structure}

The project design staff can vary, therefore remote design requirements should be further supported based on the local area network. A Virtual Private Network (VPN) is used to communicate with the design unit headquarters and a remote designer. The VPN establishes a temporary secure connection through a public network (usually the Internet), which is a safe, stable tunnel going through the complicated public network (VPN is an expansion of enterprise networks), and forms a wide area communication network for the project design. The network communication structure is used for the whole system of the project design, as shown in Figure 4.

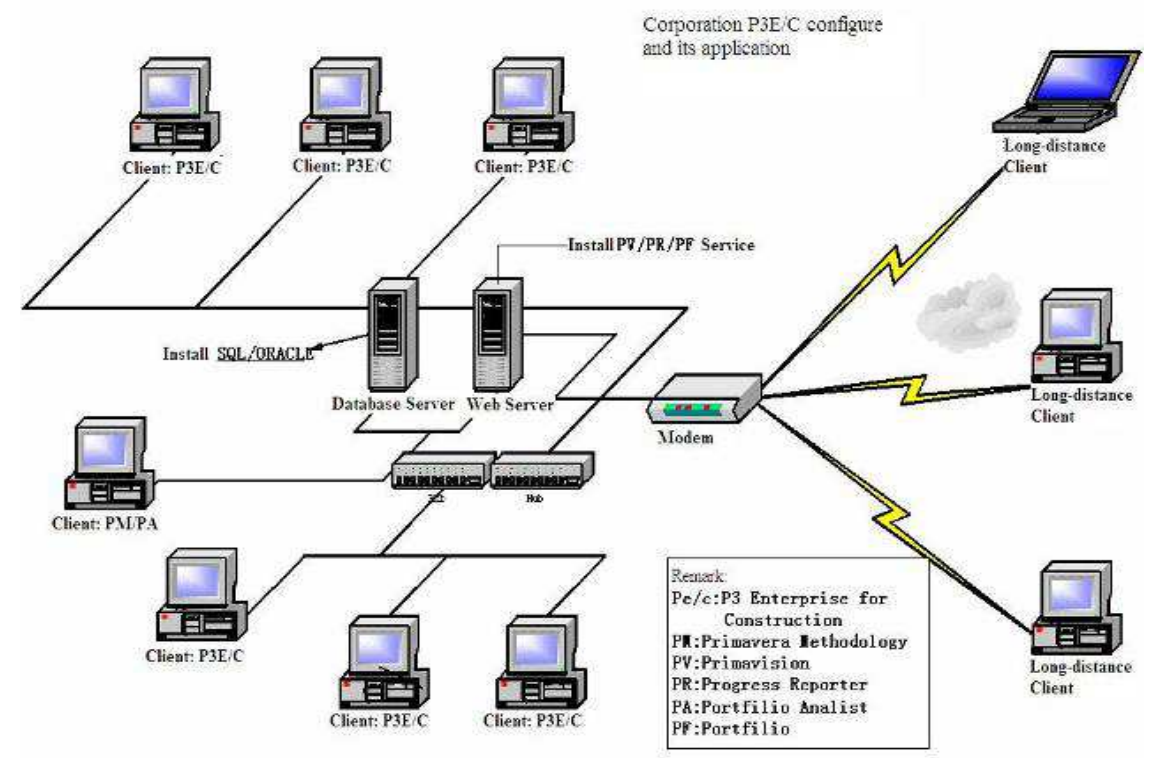

Fig. 4. Structure diagram of a project design management system network for a large hydropower station.

\subsubsection{System operation and development platform}

On the basis of investigation and comparison, the realization of this system uses P3E/C as the platform for system operation and development. The P3E/C software platform, with 
perfect function capability, is a product of the America Primavera Company, which integrates with advanced project management thinking and methodology. Based on the structural design, using the $\mathrm{P} 3 \mathrm{E} / \mathrm{C}$ platform is the best choice for realizing the core function of a production management system for a design project. P3E/C can realize many functions, such as scope management, plan/schedule management, quality control, personnel evaluation, portals, statistical analysis (such as Earned Value Analysis), and security/access control. Combining the use of P3E/C with the case study from the hydropower station engineering design project in the Survey and Design Institute of Central South China, resulted in no less than 20 concurrent users of P3E/C for the project design and management staff. The further development of the system portal, partly for statistical reports, and other information system interfaces in the system, will use Microsoft ASP.NET platform in its realization.

Application server installation included Weblogic and P3E/C components: MyPrimavera and TeamMember server (including Collaborator and TimeSheet). There are two types of client: the LAN client (C/S) and Internet client (B/S). The LAN client needs to install the $\mathrm{C} / \mathrm{S}$ client and for a manager, project manager or planning personnel, the PM/PA and MM components need to be installed. The other client uses the browser client.

\subsection{System function realization method based on P3E/C}

The production management information system for project design cannot be called a complete project management information system, because it focuses on the production process control of the design project, integration of quality management, staff performance appraisal, and production management. Unlike the latter system, it does not include the management of project funds and complete human resource management, and contains only some of the requirements of project information management. The system is a kind of management system which has a professional basis and adapts to the changes in an enterprise organization's form over a considerable range. It is not only suitable for the existing professional situations, but can also adapt to the project management organization form, and even fit with the organizational structure in existing professional design divisions. Its purpose is as follows:

- To simplify the production links.

- To devolve the implementation of the production organization to an individual level.

- To decompose the distribution and distribution examination at different design stages in existing professional divisions into processes or process packages.

- To implement the job performance appraisal at an individual level.

- To turn the implementation of quality management into processes or process packages.

- To integrate planning control, quality management, employee performance and product filing during production process into an organic whole.

- To form a standard information management system from the production organization system.

- And finally, to help the hydropower design company save energy in its activities of exploring markets, gradual transitions in business orientation, and encourage research and development in science and technology in order to improve the company's competiveness. 
Project management will be facilitated by the production management information system, which is critical to the reorganization of production processes, so that the production process of the design project can be organized in accordance with the requirements of the procedure. Thus, it can not only inherit the advantages of general professional management, but also involve the subtle links of process management. The management focus has been shifted to product demands, while the staff's attention is diverted from pure obedience on distribution to paying active attention to the demands of related procedures.

According to the requirements and objectives, the corresponding functional subsystems are divided with reference to the knowledge system of project management. The logical relationships are as shown in Figure 5 below.

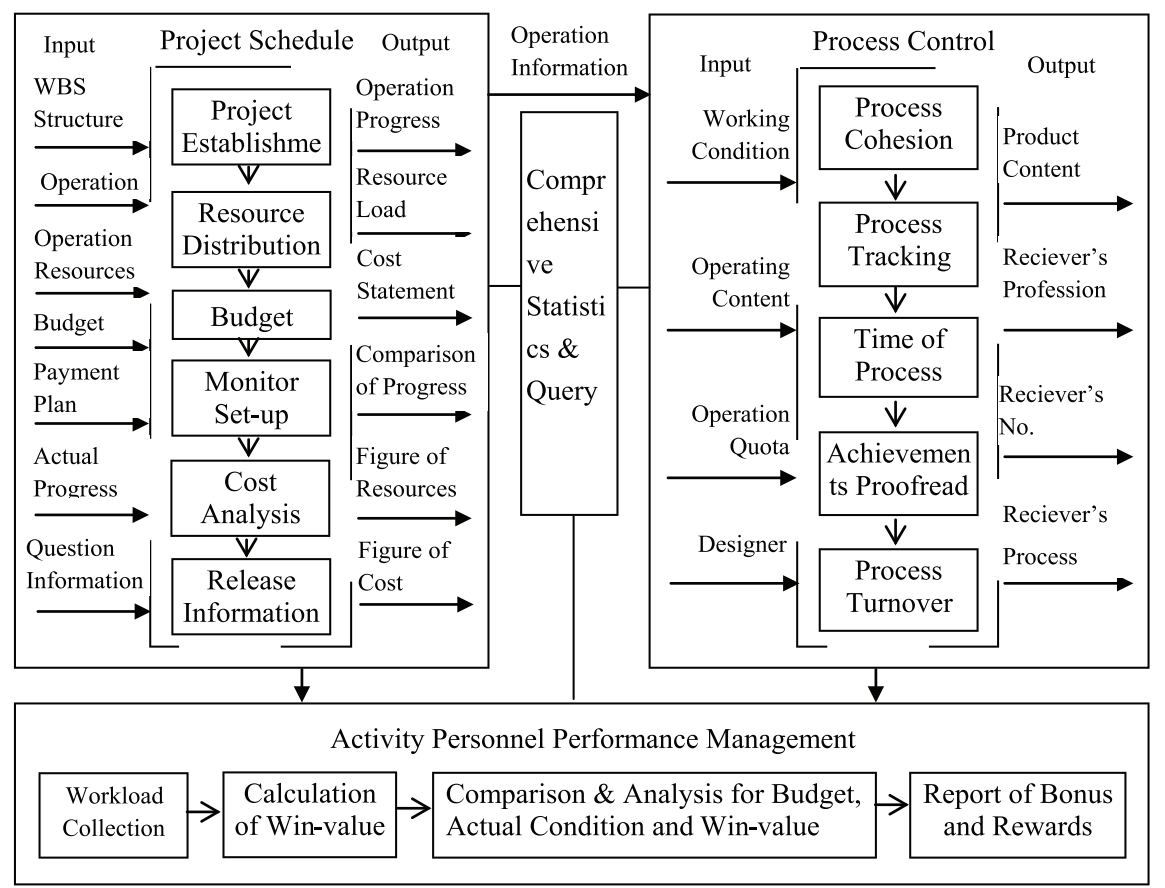

Fig. 5. System function structure diagram based on the P3E/C.

\subsubsection{Project schedule}

The project schedule includes basic information on the project, such as EPS, OBS, WBS, staffing and resource plan, schedule distribution and release etc.

The project schedule is realized through the function of WBS in the PM component of $\mathrm{P} 3 \mathrm{E} / \mathrm{C}$. The WBS is a kind of hierarchical structure coding which decomposes the project scope step by step. WBS is a mesh elements grouping, designed for delivering the final product, which organizes and defines the scope of the project. Unlisted WBS work is excluded from the scope of the project. Therefore, setting up the WBS is not only the main content for making a plan, but the important basis for defining later operations (processes). 
In P3E/C the WBS function design sets up a special WBS window to prepare the WBS for the project.

WBS code uses: project code + design phase code + the structure of process code. It is a three layer code, which uses the P3E/C WBS to realize it directly. The timing plan of the project will be realized by the following steps: 1 . Establish the WBS work breakdown structure; 2 . List the name of the operation; 3. Estimate operation time and arrange the work plan; 4. Optimize the work plan.

\subsubsection{Activity process control}

The process control realizes process tracking, control, decision-making, statistical analysis in process operation, manages or controls operation status such as time usage, the procedure connections, work conditions, product or achievement checking (including who designs, reviews, and provides the input conditions), and to whom the results are disseminated. The dynamics of the processes are reflected through an electronic board (network view).

The operation (TASK) is a basic design unit in P3E/C planning. It represents tasks required to be undertaken to complete the project. In general, many operations consist of a WBS, several WBS from a higher WBS until the project is fully configured.

The P3E/C operation has many attributes, corresponding to the data fields of the process table in the system. These include:, procedure code, name corresponding to P3E/C operation code and description, input/output conditions corresponding to a logical relationship in operation and precedence/successor operation; the output results corresponding to products and documents in operation, quota work corresponding to period types, operation calendar and the percentage of completion, designs/reviews corresponding to working documents.

The circulation of a process table in the system is achieved by distributing tasks automatically and periodically using the PR component in the P3E/C. Operators use P3E/C to realize timesheet approval through the PR timesheets feedback. Only an approved timesheet can be used to renew the content in P3E/C database.

\subsubsection{Performance management for activity personnel}

The system administrator establishes individual accounts for operation personnel. The system will automatically unify the work days for the process operators and the work days for auditors into their personal and statistical accounts. At the same time, the system calculates payments such as bonuses, etc. according to the settlement rules and provides a mechanism for various managers to evaluate personnel performance. Furthermore, it is easy for an employee to check information in their own accounts.

Staff performance in this system is a collection of various types of staff work hours. This part of the implementation is based on the correct definition of EPS, OBS, WBS and operations. The P3E/C earned value function is used to calculate real work hours and evaluate work performance. Through analyzing the project budget, actual and earned values, and progress delays can be determined. Comparing artificial time consumption and budgets, it is possible 
to determine whether savings have been made or overdrafts required etc. In this way, causes are easily found and remedies applied.

In addition, the use of the P3E/C custom field functions can greatly expand its applications. For example, through increasing the custom fields of operation, performance quality is evaluated by assessment and scoring, as a reference for performance evaluation. Definition of the evaluation parameters can be as follows: points, work discipline, difficulty of the work, work attitude, work intensity, coefficient of difficulty and so on. Composite evaluation marks can be obtained through an appropriate calculation formula.

\section{Conclusions}

There are two main types of platforms used at present for project design management (both at home and abroad): Microsoft's Project platform, and the American company Primavera P3E/C platform. The Project platform is focused on progress control. It is convenient to use, but can only be used on a single machine and hardly be applied to large hydropower complex project design. P3E/C provides a platform which can widely realize and develop functions, and be able to complete the design and management of large complex engineering projects via a network.

It is a new attempt to apply information technology in managing the design process of a hydropower station construction project. The main contribution of this chapter is to describe the use of the P3E/C platform for the realization of this kind of management requirement based on the large hydropower station project design case study of Hydrochina Zhongnan Engineering Corporation. Based on the systematic analysis of hydropower engineering design characteristics and research on key technologies of project design production process control, we designed a network communication mode and network structure for the operation of the system, and constructed a system operation platform. The advanced management concepts, based on the P3E/C platform, resulted in a system function structure for three core sub-systems: planning a project's progress, operation process control, and performance management for design project personnel. In this way, it provides good support for the successful production of a large hydropower station project.

\section{Acknowledgment}

The chapter is supported by the Natural Science Foundation of China (70871121, 71171202, 70921001, 71171201).

\section{References}

[1] Liu Shaoquan. The Application of P3 Progress Plan Software in the Project Management of Ertan Hydropower Engineering Project. Sichuan Water Powe,. 1998.17(4):25-27.

[2] Zhou Hougui. The Application of Primavera Software Package in the construction of Three Gorges Engineering Project. Project Management, 2003.10:21-23.

[3] Chen Zhou. The Application and Practice of P3 Project Management Software. Power Information, 2006.4(4):72-75. 
[4] Hou Xin, Chang Qianduan. Research and Implementation of Data Conversion of P3 and Enterprise Information System. Journal of Industrial Engineering/Engineering Management, 2005. Vol.19:58-61(Supplement).

[5] T Devogele, C Parent, S Spaccapietra.On spatial Database integration [J].International Journal ofGeograhica Information Science , 1998,12 (4):335-352.

[6] Tang Min. The Application of P3 Project Management Software in the Petroleum Engineering Design. China Science and Technology Information, 2005(13):23-23. 


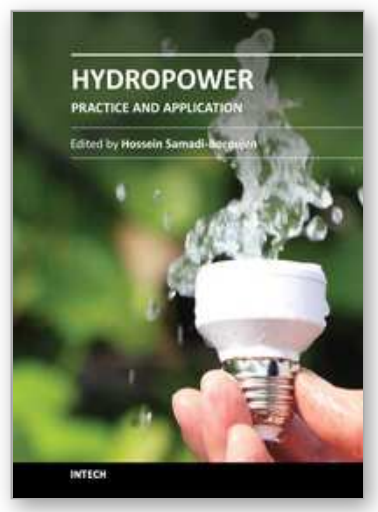

\author{
Hydropower - Practice and Application \\ Edited by Dr. Hossein Samadi-Boroujeni
}

ISBN 978-953-51-0164-2

Hard cover, 320 pages

Publisher InTech

Published online 09, March, 2012

Published in print edition March, 2012

Hydroelectric energy is the most widely used form of renewable energy, accounting for 16 percent of global electricity consumption. This book is primarily based on theoretical and applied results obtained by the authors during a long time of practice devoted to problems in the design and operation of a significant number of hydroelectric power plants in different countries. It was preferred to edit this book with the intention that it may partly serve as a supplementary textbook for students on hydropower plants. The subjects being mentioned comprise all the main components of a hydro power plant, from the upstream end, with the basin for water intake, to the downstream end of the water flow outlet.

\title{
How to reference
}

In order to correctly reference this scholarly work, feel free to copy and paste the following:

Xuanhua Xu, Yanju Zhou and Xiaohong Chen (2012). Project Design Management for a Large Hydropower Station, Hydropower - Practice and Application, Dr. Hossein Samadi-Boroujeni (Ed.), ISBN: 978-953-51-01642, InTech, Available from: http://www.intechopen.com/books/hydropower-practice-and-application/projectdesign-management-for-a-large-hydropower-station

\section{INTECH}

open science | open minds

\section{InTech Europe}

University Campus STeP Ri

Slavka Krautzeka 83/A

51000 Rijeka, Croatia

Phone: +385 (51) 770447

Fax: +385 (51) 686166

www.intechopen.com

\section{InTech China}

Unit 405, Office Block, Hotel Equatorial Shanghai

No.65, Yan An Road (West), Shanghai, 200040, China

中国上海市延安西路65号上海国际贵都大饭店办公楼405单元

Phone: +86-21-62489820

Fax: +86-21-62489821 
(C) 2012 The Author(s). Licensee IntechOpen. This is an open access article distributed under the terms of the Creative Commons Attribution 3.0 License, which permits unrestricted use, distribution, and reproduction in any medium, provided the original work is properly cited. 